IFN Working Paper No. 664, 2006

\title{
Innovation Performance and Government Financing
}

Roger Svensson 


\title{
Innovation Performance and Government Financing
}

\author{
Roger Svensson * \\ Research Institute of Industrial Economics \\ P.O. Box 55665, SE-102 15 Stockholm, Sweden \\ roger.svensson@riie.se
}

February 2006

Revised September 2006

Key words: Patents, commercialization, innovations, performance, external financing, government intervention.

JEL: 031, 038, G30, M18.

\begin{abstract}
External financing is important when inventors and small technology-based firms commercialize their inventions. However, the private information of inventors about the quality of their products causes information asymmetries and moral hazard problems. To help compensate for potentially non-existing capital markets, the Swedish Government has intervened by offering loans with different terms to firms and inventors. This paper analyzes the association between various forms of external financing and performance in profit-terms when patents are commercialized. The empirical work is based on a patent survey sent to Swedish inventors and small firms, where the response rate is $80 \%$. The estimations show that projects with soft government financing in the R\&D-phase have a significantly inferior performance compared to projects without such financing, whereas those receiving government loans on commercial terms perform as the average. Distinguishing between governmental financing alternatives with different terms makes it possible to draw the conclusion that government failure primarily depends on bad financing terms, rather than bad project selection. A policy implication is therefore that public loans should be granted on commercial terms already in the R\&D-phase of projects.
\end{abstract}

\footnotetext{
* Associate Professor; Research interests: entrepreneurship, small business, patents, service sectors.

The author would like to thank Erik Mellander, Magnus Henrekson, Tino Sanandaji and the participants at the CBER conference in Copenhagen and the NCSB conference in Stockholm for constructive comments. Jakob Eliasson provided excellent research assistance. Marianne and Marcus Wallenberg's Foundation and The Bank of Sweden are acknowledged for generous financial support.
} 


\section{Introduction}

Firms and inventors file patents for their inventions for different reasons. One reason is to eventually introduce the invention on the market, thereby turning it into an innovation. Patenting is then a method for securing the ownership of incomes and getting sufficient incentives to commercialize the invention. Owners may also file patents for strategic, defensive reasons. They might want to deter competitors from using the invention, intend to use shadow-patents, serving to protect other similar patents.

Previous studies have attempted to estimate private market values of patent rights by: 1) sending questionnaires directly to the owners (see, e.g. Griliches, 1990); 2) empirically estimating how the profit or the market value of the firm depends on patents and innovations (see, e.g. Griliches et al. 1987; Hall 1993); or 3) analyzing the renewal of patents (Pakes, 1986; Schankerman and Pakes, 1986). Few previous studies have analyzed how different explanatory factors influence the value of patents or innovations. A further drawback when studying renewal fees is that the observer cannot know whether the patents are commercialized or serve other purposes. In the long run, a sufficient share of patents must be commercialized into useful products if they are to contribute to economic welfare.

The purpose of the present study is to analyze how different strategies and background characteristics influence the performance of patent commercialization in profit-terms. The term commercialization here implies that the owners of the patent have introduced an innovation in an existing or in a new firm, licensed or sold the patent. Patents rather than inventions are chosen as the unit of observation, since the former are much easier to identify and track. In the empirical analysis, a unique database on Swedish patents granted to individual inventors and small firms is used. Information about individual patents has been collected. This includes data on if the patents were commercialized and if so whether the commercialization was successful or not. Using discrete statistical models, it is empirically examined how different explanatory factors (e.g., commercialization mode, financing, firm type, activity of inventors) affect the market performance. To the best of my knowledge, such an empirical analysis has never previously been attempted or carried out.

The specific purpose is to analyze how external financing influences the commercialization. In the previous empirical literature, external financing has empirically been shown to be important for patenting (e.g. Kortum and Lerner). However, such financing has not been empirically related to the performance of commercialization.

Patents, like R\&D projects, are characterized by high costs in the early R\&D-phase as well as high uncertainty about future incomes. Lack of financial resources is one of the major 
obstacles when innovations are to be introduced on the market, especially for small firms and individual inventors. Since inventors have more knowledge about the patent than potential external financiers, problems related to adverse selection and moral hazard are likely to be prevalent. The search and transaction costs for finding interesting projects and evaluating the technical and commercial potential are large for external financiers (Kaplan and Strömberg, 2001).

Different nations have applied various strategies to compensate for imperfect capital markets and to bridge the gap between inventors and external financiers (Braunerhjelm, 1999, and Bottazzi, Da Rin, and Hellmann, 2004). In the United States, the government has facilitated private market solutions and the growth of private venture capital firms (Gompers and Lerner 2001). In Sweden, however, the government has instead intervened in the form of financial assistance and loans. Some of the public loans are market-oriented, whereas other loans have soft terms, e.g., the borrower can avoid repayment of the loan if the project fails. Such terms are likely to create further moral hazard problems. Another interesting question is whether the government is competent to find and evaluate appropriate projects to grant funds, since public employees have no profit incentives. These factors may lead to a negative selection of projects. By distinguishing between governmental financing with soft and market-oriented terms, hypotheses are set up and tested of whether a possible government failure depends on bad financing terms or a bad choice of projects in general.

The paper is organized as follows. Previous studies about commercialization of patents and adequate theories are discussed in section 2. The database and basic statistics are described in section 3. The statistical model and hypotheses are set up in section 4. The empirical estimations are shown in section 5, and the final section concludes.

\section{Previous studies and theories}

\subsection{Previous studies}

Earlier patent studies have mostly used data from one or several national patent offices. This means that the researchers do not know whether the patents have been commercialized, or whether the commercialization was successful. Patent databases with detailed information (which are not available from the national patent offices) have seldom been collected. The few previous studies with such databases have focused on estimating the profits from patenting, or the market value of patents, rather than analyzing how different strategies are related to the outcome of the commercialization (Rossman and Sanders, 1957; Sanders et al., 
1958; Sanders, 1962, 1964; Schmookler, 1966; Cutler, 1984; SRI International, 1985). The main conclusions of these studies are that the mean value of patents is positive, but the median value is zero or negative, indicating a very large dispersion in economic value.

Morgan et al. (2001) describe the rate of commercialization of American patents across different groups. Industrial patents had a commercialization rate of $48.9 \%$, whereas the rate in the education sector was $33.5 \%$. However, the authors never try to relate this commercialization rate to other explanatory factors and do not estimate any survival model perhaps due to data constrains. Using a survival model, Svensson (2004) estimates how different factors affect the commercialization decision. It was concluded that firms commercialize faster, and to a greater extent, than individual inventors, but also that the more government financing the inventors received during the R\&D-phase, the longer it took until commercialization was initiated. Patents financed by the government were also more likely never to be commercialized. The explanation for this behavior could be found in either the loan terms, where the inventors could avoid repayment if the patent was never commercialized, or in a negative selection of projects.

\subsection{Performance of the commercialization compared to renewal of patents}

Another strand of the patent literature has analyzed the renewal of patents (see e.g. Griliches, 1990). The owners must pay a renewal fee to keep their patents in force - in many countries every year. Griliches argues that owners will only renew their patents if it is economically profitable. The percentage of renewed patents indicates how many patents have a positive economic value after a given number of years. Schankerman and Pakes (1986) show that about half the European patents are still renewed after 10 years, but only 10 percent are renewed in the whole statutory period (20 years). The models in Pakes (1986) and Schankerman and Pakes (1986) are based on the assumption that more valuable patents are renewed for longer periods than less valuable patents. The authors estimate both the distribution of the patent values and their rate of depreciation. The main conclusions of these studies are that most patents have a low value and that it depreciates fast, and only a few have a significant high value. In other words, the value distribution of patents is severely skewed to the right.

There are some problems with the renewal measurement. First, the renewal fee is a relatively modest annual cost; so that even those patents that were renewed for the whole statutory period may have a low absolute value. Second, there is an identification problem, where the value of the patent above a certain threshold value cannot be estimated based on 
renewal alone. Finally, patents that are not renewed need not necessarily have a low value, as the product based on the patent might be commercialized with a short lifetime. In this lifetime, the product could either have been profitable for the owner or not.

Although most commercialized patents can be expected to be renewed and most noncommercialized patents to be killed, there are many exceptions, as will be shown in section 3 . Measuring the outcome of the commercialization does not take into account that also noncommercialized patents might be profitable for the owner. Some patents are never commercialized, although they are renewed during the whole statutory period for strategic reasons. They serve, for example, as shadow patents and protect similar patents. Renewal studies take this phenomenon into account. However, the strategy to apply for defensive patents is primarily used by large firms (Svensson, 2002). Shadow-patents are relatively rare among individual inventors and small firms in our database (more about this in section 3). As previously noted; Irrespective of how the success, or the value, of patents has been measured, these studies have seldom related this measure to explanatory factors. An exception is Maurseth (2005), where patent citations across and within technology fields turn out to have different implications for the renewal of patents.

\subsection{Patents and external financing}

Inventions, like R\&D-projects, are typically characterized by high costs and no incomes in the early R\&D-phase, and high uncertainty about future incomes. Besides technological problems, lack of financial resources is one of the largest problems when the inventions are to be commercialized, i.e., innovations are created by the inventions and introduced into the market. Clearly, inventors have more knowledge about the invention than external financiers, licensees and buyers, leading to asymmetrical information and adverse selection problems. The search and transaction costs of finding interesting projects and evaluating the technical and commercial potential are, in other words, large for external actors. Therefore, market imperfections are likely to exist on the market for financing of innovation projects. To overcome market failures and the gap between inventors and external financiers, different countries have applied different strategies (Braunerhjelm, 1999, and Bottazzi, Da Rin, and Hellmann, 2004). In the United States, the government has facilitated private market solutions and the growth of private venture capital firms (Gompers and Lerner 2001). In Sweden, the government has intervened by offering financial assistance and loans to inventors and small technology-based firms. 
In the early R\&D-phase - before manufacturing has started - the Swedish Government offers financial assistance and loans with soft loan terms to inventors and small technology-based firms. Considering the soft loans, the borrower pays a subsidized interest rate and begins to pay back the loan some years after the commercialization has started. However, if there is no commercialization or if the commercialization fails, the borrower needs not pay back the loan at all. If the borrower does receive incomes during the commercialization, the repayment of the loan is connected to product turnover.

The soft loans offered by the Swedish government authorities are described in detail in Appendix. To give soft loans to a firm or an inventor in the R\&D-phase, the government authorities had two selection criteria: 1) the project should have a good chance of success both technically and commercially; and 2) the project is a high-tech project. The government financing could cover up to $50-70 \%$ of the total R\&D-costs depending on which government authority provided the loan. Thus, there was a requirement of co-financing by the borrower or somebody else, but this financing was allowed to take the form of unpaid labor incomes. This is a cost which cannot be controlled by the government authority (moral hazard problems). Practically, the government loans could therefore cover more than $80 \%$ of the project's total $\mathrm{R} \& \mathrm{D}$-costs

The design of the loan where repayment is connected to turnover rather than the profit means that projects with a low or medium expected profit level would probably not be commercialized at all, since the repayment of the loan would then erase the whole profit. However, this will not prevent commercialization if the expected profit level is high. Due to the design of the loans from government institutions, problems related to moral hazard are likely to emerge. Inventors, who have received soft loans from the government, need not care about further commercialization of the patent, since they know that there is a high probability of their not having to pay back the loans at all. The main conclusion in Svensson (2004) was that soft financing from the government in the R\&D-phase reduces the probability of commercialization. In the present study, it is also hypothesized that the repayment terms of soft financing should give the owners less incentive to make an effort during commercialization.

The government also offers entrepreneurs more market-oriented loans during the commercialization phase. These loans must be repaid, and have interest rates similar to those charged by commercial banks. The terms of such loans thereby do not detrimentally affect the borrowers' incentives to perform well when innovations are introduced into the market. 
The government-financing institutions are not profit maximizing, and tend to have fewer incentives to search for and select good patent projects to which they lend money. The employees do not invest their own private money. On the other hand, private venture capital firms and especially business angels are likely to be more careful than government institutions about which patent projects in which they invest. In addition, they tend to have a more active, and advisory, role already in the early phases of business projects. It is not unlikely that there is some form of negative selection, where the government tends to lend money to worse projects.

Based on the terms of government financing and the performance of the commercialization, two mutually exclusive hypotheses are set up:

Hypothesis A: If projects with soft government financing fail during commercialization, but projects with market-oriented government financing do not, then the failure should depend on bad government loan terms.

Hypothesis B: If projects with government financing - irrespective of the terms - fail during commercialization, then the failure is caused by the government choosing bad projects.

A common opinion is that the government selects among projects which have been turned down by private investors. Therefore, loans from government would go to relatively less profitable projects. However, Kaivanto and Stoneman (2006) have shown that soft government loans, as described above, are more attractive for inventors, and have a higher pecking order, than equity financing from private venture capitalists. ${ }^{1}$ The authors give three reasons why such soft loans are attractive for firms and inventors. First, the patent owners do not lose control of the project. Secondly, the repayment is a variable cost, not a fixed cost, and do not increase the financial risk of the firm. Thirdly, debt usually requires collateral financing. However, the soft government loans are backed by future incomes and, therefore, do not require collateral.

\footnotetext{
${ }^{1}$ The authors call this kind of government financing for "sales contingent claims" (SCC), but it is almost identical to the soft loans provided by the Swedish government.
} 


\section{Database and descriptive statistics}

When analyzing the commercialization of patents, it is necessary to have a detailed database about individual patents. ${ }^{2}$ In a previous pilot study (Svensson, 2002), the commercialization started within five years after the application year for most patents. According to Pakes (1986), most of the uncertainty of the value of the patent is resolved during the first three-four years after the patent application. Therefore, patents granted in 1998 were chosen for the current database. ${ }^{3}$ In 1998, 2760 patents were granted in Sweden. 776 of these were granted to foreign firms, 902 to large Swedish firms with more than 1000 employees, and 1082 to Swedish individual inventors and firms with less than 1000 employees. Information about inventors, applying firms and their addresses for each patent was bought from the Swedish Patent and Registration Office (PRV). Thereafter, a questionnaire was sent out to the inventors. ${ }^{4}$ In the pilot survey carried out in 2002, it turned out that large Swedish firms refused to provide information on individual patents. Furthermore, it is impossible to persuade foreign firms to fill in questionnaires about patents. These firms are almost always large multinationals firms. Therefore, the population consists of 1082 patents granted to Swedish individual inventors and firms with less than 1000 employees. This sample selection is not a problem, as long as the conclusions are drawn for small firms and individuals.

In the questionnaire, we asked the inventors about the work place where the invention was created, the financing of the invention during the R\&D phase, whether the patent was commercialized, which kind of commercialization mode was chosen, how the commercialization was financed, as well as the outcome of the commercialization. As many as 867 of the inventors filled in and returned the questionnaire, i.e., the response rate was $80 \%$ (867 out of 1082). This response rate is satisfactorily high, if taking into account that such a database has seldom been collected before and that inventors or applying firms usually consider information about inventions and patents to be secret. The fall-off primarily depends

\footnotetext{
${ }^{2}$ All inventions do not result in patents. However, since an invention, which does not result in a patent, is not registered anywhere, there are two problems in empirically analyzing the invention rather than the patent. First, it is impossible to find these new ideas, products and developments among all firms and individuals. On the other hand, all patents are registered. Second, even if the "inventions" are found, it is difficult to judge whether they are sufficient improvements to be called inventions. Only the national and international patent offices make such judgements. Therefore, the choice of the patent rather than the invention is the only alternative for an empirical study of the commercialization process.

${ }^{3}$ The year the patent is granted is used here, but patents filed in a specific year might have been preferable. The choice of patents granted in a specific year is, however, not a problem in the statistical estimations.

${ }^{4}$ Each patent always has at least one inventor and often also an applying firm. The inventors or the applying firm can be the owner of the patent, but the inventors can also indirectly be owners of the patent, via the applying firm. Sometimes the inventors are only employed in the applying firm, which owns the patent. If the patent had more than one inventor, the questionnaire was sent to one inventor only.
} 
on the addresses from PRV being out of date, and to a smaller degree on inventors refusing to reply.

The application year of the 867 patents is described as light-gray staples in Figure 1. $85 \%$ of the patents were applied for between 1994 and 1997. In 2003, commercialization had been started for 530 of these patents. The starting year of the commercialization is represented by dark staples, which almost follow a normal distribution. Although the last year of observation is 2003 , it is not likely that many of the 337 non-commercialized patents will be commercialized after 2003.

$* * * * * * * *$ [Figure 1] $* * * * * * * *$

The commercialization rate of the 867 patents is described across firm groups and ownership in Table 1 . As many as 408 patents (47\%) were granted to individual inventors, ${ }^{5}$ and 116, 201, 142 patents were granted to medium-sized firms (101-1000 employees), small firms (11-100 employees) and close companies (2-10 employees), respectively. The commercialization rate of the firm groups is between 66 and $74 \%$, whereas the rate of the individuals is not higher than $52 \%$. A contingent-table test suggests there to be a significant difference in the commercialization rate between firms and individuals. The chi-square value is 30.55 (with 3 d.f.), significant at the one-percent level.

$* * * * * * * *[$ Table 1] $* * * * * * * *$

At the end point of observation (year 2003), the inventors answered to estimate whether the outcome of the commercialization would likely become a profit, a break-even or a loss outcome. If they did not know, the reply was registered as an uncertain outcome. ${ }^{6}$ In Table 2, discrete values of the outcome in profit terms are described across firm groups. It would have been desirable to measure the outcome in money terms. However, such information was impossible to collect, a conclusion drawn already when undertaking the pilot study (Svensson, 2002). ${ }^{7}$ Since the patents were granted in 1998 and some of them were commercialized even later, the outcome is uncertain for around $12 \%$ of the commercialized

\footnotetext{
${ }^{5}$ The group of individual inventors includes private persons, self-employed inventors as well as two-three inventors, who are organized in trading companies or private firms without employees.

${ }^{6}$ For a vast majority of the patents, the commercialization had reached such a stage that there was no uncertainty at all about the outcome.

${ }^{7}$ It is very complicated to estimate profit flows, because most firms have many products in their statement of account, and many individuals do not have any statement of account at all.
} 
patents. Many of these uncertain patents would probably later (after 2003) be categorized in the break-even or loss groups. As described in the table, the outcome is quite different across firm groups, where the group of individual inventors has the worst outcome, but there may be other underlying factors explaining this difference, e.g., the commercialization mode or the fact that the new product replaced an earlier one.

$* * * * * * * *[$ Table 2$] * * * * * * * *$

In Table 3, outcomes are described across external financing. It is obvious that projects with private venture capital perform better than those with government financing. However, only projects with private venture capital in the R\&D-phase can match the average in Table 2. On the other hand, external financing is primarily provided to close companies and individuals, which in general have a worse performance than small and medium-sized firms.

$* * * * * * * *[$ Table 3$] * * * * * * * *$

In Table 4, commercialized patents are compared to renewed patents. Owners must pay an annual renewal fee to the national patent office to keep their patents in force. If the renewal fee is not paid in one single year, the patent expires. As expected, renewed patents (71\%) have been commercialized to a higher degree than expired ones $(49 \%)$. The chi-square value below the table shows there to be a strong correlation between commercialized and renewed patents. However, $36 \%$ of the commercialized patents are already expired. This is either due to the products having a short lifecycle or the commercialization having failed. $41 \%$ of the non-commercialized patents are still alive. Many of these patents might be defensive patents, with the purpose of deterring competitors from using the invention or defending other patents. In the latter case, the patents serve as shadow-patents.

$* * * * * * * *[$ Table 4$] * * * * * * * *$

One objection against the measurement of success in this study would be that the patent might be profitable for the owners, even if it is never commercialized, e.g., if it serves as a shadow-patent. If this is the case, the owner should have more similarly granted patents. Among the commercialized patents in the database, $46 \%$ of the owners have at least one more similar patent. Among the non-commercialized patents, this percentage is only $33 \%$. If the 
patent had not been commercialized, the inventor was also asked: why this was the case. Among the 337 non-commercialized patents, only 15 inventors answered as one of the potential reasons for its not having been commercialized that the patent served as a shadowpatent. ${ }^{8}$ Thus, it can be concluded that keeping patents for defending other patents is not common among individuals and small firms, at least based on survey responses. This strategy is more frequent among large multinational firms (Svensson, 2002).

In Table 5, the outcome of commercialization is shown for both expired and renewed patents. The general pattern is that patents that are still alive have a higher share of successful outcomes as compared to expired patents, but the probability of a successful outcome also increases the longer was the life of the expired patent. There are however many exceptions. For example, some patents, which expired after only 1-5 years, were profitable, while many patents still renewed and commercialized have been losses for the owners. Therefore, the assumption that more valuable patents are renewed for longer periods is somewhat shaky in the renewal studies, which were discussed in section 2.2.

$* * * * * * * *$ Table 5$] * * * * * * * *$

\section{Econometric models and hypotheses}

\subsection{Econometric model}

The dependent variable, PROFIT, in the empirical estimations measures the performance in profit terms of the commercialization for the original owner of the patent. It can take on four different discrete values denoted by index $k$ :

- Profit, $k=2$;

- Break-even, $k=1$;

- Loss, $k=0$.

Since it is possible to order the three alternatives, an ordered probit model is applied. ${ }^{9}$. A multinomial logit model fails to take the ranking of the outcomes into account. On the other

\footnotetext{
${ }^{8}$ The most frequent reasons here were: 1) problems with financing (115 patents); 2) problems with marketing (75 patents); 3) problems in finding a manufacturing firm/licensor (74 patents); and 4) the product is not yet ready for commercialization (62 patents). Note that inventors may have mentioned more than one reason why the patent was not commercialized.

${ }^{9}$ There were 86 observations in the database, where the owner could not specify the expected profit level of the commercialization. These missing values could also be treated as a fourth, uncertain, outcome of PROFIT. A multinomial logit model, where all four alternatives were included, was estimated. Then we accomplished a test for independence of irrelevant alternatives (Hausmann and McFadden, 1984). When excluding the uncertain alternative in the multinomial logit model, this test cannot be rejected. Thus, the parameter estimates between the
} 
hand, an ordinary regression would treat the differences between 0 and 1 the same as that between 1 and 2 . This would be an error, since the discrete outcomes are only ranked. The ordered probit model can be described in the following way:

$$
y_{i}^{*}=X_{i} \alpha+\varepsilon_{i}
$$

where $\mathbf{X}_{\mathbf{i}}$ is a vector of patent specific characteristics. The vector of coefficients, $\boldsymbol{\alpha}$, shows the influence of the independent variables on the profit level. The residual vector $\boldsymbol{\varepsilon}_{\mathbf{i}}$ represents the combined effects of unobserved random variables and random disturbances. The residuals are assumed to have a normal distribution and the mean and variance are normalized to 0 and 1 . The vector with the latent variable, $\mathbf{y}_{\mathbf{i}}{ }^{*}$, is unobserved. The model is based on the cumulative normal distribution function, $F(X \alpha)$, and is estimated via maximum likelihood procedures. The difference with the two-response probit model is here that a parameter (threshold value), $\omega$, is estimated by $\alpha$. The probabilities $P_{i}(k)=P_{i}(y=k)$ for the three outcomes are:

$$
\begin{aligned}
& P_{i}(0)=F(-X \alpha), \\
& P_{i}(1)=F(\omega-X \alpha)-F(-X \alpha), \\
& P_{i}(2)=1-F(\varpi-X \alpha), \\
& \text { where } \sum_{k=0}^{2} P_{i}(k)=1 .
\end{aligned}
$$

The threshold value, $\omega$, must be larger than 0 , for all probabilities to be positive.

An objection against the sample and the chosen statistical model would be that the patents, which are commercialized, are not a random sample of patents, but have specific characteristics that led to them being commercialized in the first place. This could result in misleading parameter estimates. An appropriate statistical model is therefore an ordered probit model with sample selectivity (Greene, 2002). In the first step, a probit model estimates how different factors influence the decision to commercialize the patent:

other outcome alternatives are almost unaffected if the uncertain alternative is excluded. It is then no problem to exclude those patents with unknown profit-levels from the estimations. 


$$
\begin{aligned}
& d_{i}^{*}=Z_{i} \theta+u_{i} \\
& d_{i}=1 \text { if } d_{i}^{*}>0 \text { and } 0 \text { otherwise. }
\end{aligned}
$$

where $d_{i} *$ is a latent index and $d_{i}$ is the selection variable, indicating if the patent is commercialized or not. $\mathbf{Z}_{\mathbf{i}}$ is a vector of explanatory variables which influence the probability that the patent is commercialized and $\boldsymbol{\theta}$ is a vector of parameters to be estimated. $\mathbf{u}_{\mathbf{i}}$ is a vector of normally distributed residuals with zero mean and a variance equal to 1 .

From the probit estimates, the selection variable $d_{i}$ is then used to estimate a full information maximum likelihood model of the ordered probit model (Greene, 2002). ${ }^{10}$ At the same time, the first step probit model is re-estimated. The residuals, $[\varepsilon, \mathrm{u}]$ are assumed to have a bivariate standard normal distribution and correlation $\rho$. There is selectivity if $\rho$ is not equal to zero.

\subsection{Hypotheses}

The hypotheses show how an increase of the explanatory variable influences the probability that the owners will make a profit or a loss. All hypotheses and basic statistics about the explanatory variables are shown in Table 6.

$* * * * * * * *[$ Table 6$] * * * * * * * *$

Below, five variables follow measuring the involvement of external financing during the R\&D- and commercialization phases.

As discussed in section 2.3, the Swedish government institutes, which assist with financing of patent projects in the R\&D-phase, have curious loan terms. The borrower can avoid paying back the loan if the patent is not commercialized, or if the commercialization fails. If the patent is commercialized, repayment is connected to the turnover, as opposed to profit. This means that the expected return of commercialization must be higher than a threshold value - otherwise the repayment might erase the entire profit. Such financing during the $R \& D$ phase will therefore deter inventors from commercialization, which was also statistically confirmed in Svensson (2004). GOVRD takes on the value of 1 if the project had soft government financing in the R\&D-phase, and 0 otherwise. I expect only patents with an expected profit above the threshold value to be commercialized. However, the soft financing

\footnotetext{
${ }^{10}$ This is not a two-step Heckman model. No Lambda is computed and used in the second step.
} 
terms may induce fewer incentives to work hard on the commercialization. Therefore, the expected impact of GOVRD on the profit level is negative.

In a similar way, the dummy PRIVRD is a dummy that equals 1 if the project was financed through external private venture capital in the $R \& D$-phase. Private venture capitalists can be regarded as strictly profit maximizing and they only invest in, and commercialize, projects when they expect a profit. It is also likely that patents, which had external private financing during the R\&D phase, more easily attract external venture capital (from the same private venture capitalists) during the commercialization phase. However, it is not obvious that patents, which receive external private financing, should become more successful as compared to those that do not receive financing.

There is also a third kind of external R\&D-financing. OTHRD equals 1 if the project was financed through universities and research foundations, and 0 otherwise. Typically, patents created at universities have this kind of external financing. The intention of this kind of financing is not to assist a patent project, but rather to finance $R \& D$ in general. However, the financiers seldom have any control over for what the resources are actually used. It is difficult for the inventors to use the resources for patent applications, but easier to hide labor costs necessary for creating the invention within this financing. A problem with such financing is that it cannot be used for commercialization. Consequently, the inventors often stand alone without any external funds when considering commercialization. A negative parameter estimate is therefore expected on the profit level.

Two dummies showing involvement of external financing during the commercialization are included. GOVCOM takes on the value of 1 if the commercialization was supported by government loans, and 0 otherwise. In a similar way, PRIVCOM equals 1 if the commercialization was partly financed by private venture capitalists. Government financing during the commercialization is much more market-oriented in Sweden as compared to government financing during the R\&D-phase. GOVCOM might have some impact on the profit outcome, but it is difficult to specify how; for example, there might be some form of negative selection of projects, since government institutions have no profit incentives. The impact on the profit level is unsettled.

It is expected that firms, which have marketing, manufacturing and financial resources in-house, have better possibilities of becoming successful in their commercialization as compared to individuals. FIRM1 is a dummy that takes on the value of 1 for medium-sized firms with 101-1000 employees and 0 otherwise. FIRM2 equals 1 for small firms with 11-100 employees and 0 otherwise. Finally, FIRM3 is a third dummy taking the value of 1 for close 
companies with 2-10 employees, and 0 otherwise. All parameter estimates are expected to have positive effects on the profit level, since the firm dummies are here related to the reference group of individual inventors. Furthermore, the larger is the firm, the better are the possibilities of becoming successful. Thus, the parameter estimate of FIRM1 is expected to be larger that that of FIRM2 which, in turn, is expected to be larger than FIRM3.

There are four main modes of commercialization: 1) selling the patent; 2) licensing the patent; 3) commercialization in an existing firm; or 4) in a new firm. SELL is a dummy variable, which takes on the value of 1 if the patent was sold, and 0 otherwise. LICENS equals 1 if the patent was licensed and 0 otherwise. If the patent was commercialized in a new firm, $N E W$ equals 1 and 0 otherwise. The reference group here is patents commercialized in the owners' existing firms. New firms have considerably more problems to overcome as compared to existing ones. New firms should therefore have a lower profit level. There are no obvious hypotheses on how SELL and LICENS should influence the profit level. These hypotheses are therefore unsettled.

COMYEAR measures the year when the commercialization started. The later is the starting year, the fewer are the years until the end of the observation (2003). Thus, the probability of an uncertain outcome should then increase. If patent owners wait to commercialize their patent, this might depend on uncertainty about future incomes. WAITYEAR measures the number of years between the application year and the starting year of the commercialization. COMYEAR and WAITYEAR might be correlated, but need not be, since the patents have different application years. Neither COMYEAR nor WAITYEAR have any expected impact on the profit level.

According to previous studies, it is important that the inventors, who have specific knowledge about the patent, are active during the commercialization. ACTIVE is a dummy, which equals 1 if the inventors had an active role during the commercialization, and 0 otherwise. It is expected to have a positive influence on the profit level. REPLACE is a dummy that equals 1 if the product based on the patent replaces a previous product of the patent owner, and 0 otherwise. If the new product replaces an earlier product, the commercialization is expected to be facilitated. The owner then already has customers, distribution channels, marketing, etc. A positive impact on the profit level is expected.

MOREPAT is an additive dummy, which equals 1 if the inventors or the applying firm have more competitive Swedish patents in the same technology area, and 0 otherwise. Applying for many similar patents is a strategy often chosen by owners - especially large firms - that want to protect a main patent. These additional patents are called shadow patents 
and are seldom commercialized. Given that a patent is commercialized, many similar patents imply a strong position and defense in the market and should increase the probability of success. Many similar patents can also be an indication that the owners have more knowledge and experience of the area. Thus, a positive impact on PROFIT is expected.

A further variable measuring the complexity of the product is included. PARTSYST equals 1 if the patent is a part of a larger system/product, and 0 otherwise. The dummy variable $K O M P L$ takes on the value of 1 if complementing patents are needed to create a product, and 0 otherwise. INVNMBR measures the number of inventors of the patent. The expected impacts on the dependent variable are unsettled.

Some specific characteristics of the inventors are also included in the mode. $S X$ measures the share of inventors, who are females. No specific influence on PROFIT is expected. ETH measures the share of inventors who belongs to ethnical minorities, i.e. an ethnical background other than West European or North American. It is expected that ethnical minorities have more problems with the commercialization. Thus a negative impact on PROFIT is expected.

Different technologies are likely to be connected with different payoffs and risks. Consequently, the technology class can affect the profit level, given that the patent is commercialized. Patents are divided into 30 technology groups according to Breschi et al. (2004). These groups are based on the patents' main IPC-Class. However, all technology groups are not represented in the dataset and some groups do not have enough observations. ${ }^{11}$ Therefore, only 16 groups and 15 additive dummies are used in the present study.

The data is also divided into six different kinds of regions according to NUTEK (1998): Large-city regions, university regions, regions with important primary city centers, regions with secondary city centers, small regions with private employment, and small regions with government employment. Five additive dummies are included for these six groups in the estimations.

Something should also be said about the explanatory variables, which are expected to affect the commercialization decision $(d)$ and are included in the probit equation when taking the selection problem into account. These variables are based on the model in Svensson (2004), where the commercialization decision was analyzed using survivals models. FIRM1, FIRM2, FIRM3, GOVRD, PRIVRD, OTHRD, MOREPAT, INVNMBR and KOMPL the region and technology dummies, as described above, are included in the probit equation.

\footnotetext{
${ }^{11}$ A technology class must have at least one observation in each of the four outcome alternatives, in order to obtain an own technology dummy. Technology classes without enough observations are instead merged with other closely related classes (Breschi et al., 2004).
} 
Furthermore, time dummies for the application year, and another variable (OWNER) is added. $^{12}$ On the other hand, variables characterizing the commercialization, e.g. commercialization mode (SELL, LICENS and NEWFIRM), ACTIVE, REPLACE, etc., cannot be included. This means that different explanatory variables are included in the probit and ordered probit equations.

\section{Empirical estimations}

To test for robustness, at least three variants of all models are estimated. In these variants, region dummies (A), technology dummies (B) and both region and technology dummies (C) are included. Furthermore, the model is estimated both without and with selectivity. In the latter case, the previous inclusion of dummy variables (A-C) is then repeated (D-F). An attempt to include additive dummies for unique owners (firms/inventors) in the estimations was also done, but this did not work out well due to multicollinearity problems. ${ }^{13}$

The results of the ordered probit model are shown in Table 7. Focusing on the financial variables, soft government financing in the R\&D-phase, GOVRD, has a negative influence on the profit level, which is significant at the one-percent level. On the other hand, government financing in the commercialization phase - represented by GOVCOM - never has any significant impact on the profit level. These results also hold when we take account of sample selectivity (Models D-F). The later government financing is much more marketoriented than the earlier soft R\&D-financing. Thus, it seems that it is the terms of the financing that lead to the bad performance of government financed projects rather than the government choosing to lend money to bad projects. In other words, Hypothesis A dominates Hypothesis B (see section 2.3).

One objection against the results is that the government selects among projects, which have been turned down by private investors. It would then be likely that government loans will go to less profitable projects. However, Kaivanto and Stoneman (2006) have shown that the pecking order is higher for soft government loans than for equity financing from venture capitalists, as discussed in section 2.3. Another objection is that it would be natural that projects with financing given in an early uncertain phase have a worse performance than

\footnotetext{
${ }^{12}$ OWNER measures how large a share (in percent) of the patent that is directly or indirectly owned by the inventors.

${ }^{13}$ Among the 530 commercialized patents in the sample, there are 460 unique owners (firms/inventors). 418 owners have only one commercialized patent in 1998, 29 owners have two patents, and only 13 owners have at least three patents. Dummies can only be assigned to those 42 owners with at least 2 patents. However, when including dummies for unique owners, the models were characterized by severe multicollinearity problems with extremely high standard errors for the owner dummies. These problems occurred even when all technology and region dummies were excluded and when dummies were included only for those 13 owners with at least three commercialized patents.
} 
projects with financing given in a later, less uncertain phase. In order to solve this problem, sample selection is included in the last three models (D-F). This means that the model takes account of when the financing occurred. ${ }^{14}$ Furthermore, the results of the private financing do not show that early financing (PRIVRD) has a worse performance than late financing (PRIVCOM). External private venture capital, regardless of when it was invested, does not have any influence on the profit level.

Turning to the other variables, all firm group dummies have positive and strongly significant impacts on the profit level, implying that patents commercialized by firms have a higher probability of success as compared to patents commercialized by individual inventors. Furthermore, the parameter of FIRM1 is always significantly different from the parameter of FIRM3. FIRM2 is significantly different from FIRM3 at the five-percent level in two out of six runs. Considering the commercialization mode, licensing or selling the patent has a positive impact on the profit level compared to commercializing in an existing firm - the parameters are always significant at the five-percent level. The parameter of $N E W$ is negative, but never significant. By recalculating the parameter estimates, however, it is easily seen that selling or licensing the patent has a positive influence on the profit level as compared to the new firm alternative - the differences are always significant at the one-percent level. The dummy variables, ACTIVE and MOREPAT, have positive and significant influences on PROFIT. Thus, an active role of the inventors during the commercialization and whether the owner has more similar patents are strategies or facts that give a higher probability for a successful commercialization.

$* * * * * * * *[$ Table $7 * * * * * * * *$

An alternative interpretation of the bad performance of projects with government $\mathrm{R} \& \mathrm{D}$-financing is that the government might assist patent projects with an average higher risk level. R\&D-financing is mostly provided to projects owned by individuals, which should be expected to have a higher risk. Therefore, the effect of GOVRD is separately estimated for firms and individuals, by using an interaction dummy in Table 8. GOVRD has a significant influence on the profit level for both firms and individuals. The parameter estimate is more negative for firms, but the difference is never significant.

$* * * * * * * *[$ Table $8 * * * * * * * *$

\footnotetext{
${ }^{14}$ Only those projects with government R\&D financing, which have been commercialized, are compared with in the estimations.
} 
Size interpretations of the estimated parameters are also necessary. The marginal effects of the significant explanatory variables on the probability of the profit level are shown in Table 9. To simplify, these effects are calculated around the means of the $\mathbf{x}_{\mathbf{i}}$ :s (Greene, 1997). ${ }^{15}$ If GOVRD changes from 0 to 1 in Model F, the probability of a successful outcome, $P(2)$, decreases by 18 percentage units, the probability of a break-even outcome, $P(1)$, increases by 4 percentage units and the probability of an unsuccessful one, $P(0)$, increases by 22 percentage units. The effect is larger for firms than for individuals, though the difference between these two groups is not significant. Similar interpretations of the marginal effects can be made for the other dummy variables in Table 9. For example, the probability of a success increases by 20 percentage units if the patent is sold as compared to commercializing in an existing firm.

$* * * * * * * *[$ Table 9$] * * * * * * * *$

\section{Concluding remarks}

This study has empirically estimated the importance of various background factors for a successful commercialization of patents, something never previously done. A unique database on Swedish patents owned by individual inventors and small firms was used. The database is based on a patent survey, where the response rate is as high as $80 \%$. The data made it possible to observe whether commercialization led to a successful, a break-even or an unsuccessful outcome in profit terms.

By using discrete statistical models, it is concluded that projects with soft government financing in the R\&D-phase have a significantly worse performance than projects without such financing. The marginal effect on the probabilities is not small. For example, if the patent had soft government loans, the probability of a profitable commercialization decreases by 18 percent units. On the other hand, projects with more market-oriented government loans granted in the commercialization phase have the same performance as the average. By estimating separate effects for individual inventors and firms, the different risk level of the types of projects is taken into account. It turns out that the negative influence of government R\&D-financing on the profit level is always significant for both firms and individual inventors.

\footnotetext{
${ }^{15}$ Since the probit function is non-linear, the effect of a unit increase on the probability will vary depending on the point on the distribution. The effect is the largest in the middle of the distribution function, where $v_{i}$ is close to 0 and $P_{i}(1)$ is close to 0.5 .
} 
The fact that the estimations include projects with different kinds of government financing - soft and market-oriented financing terms - enables us to discriminate between two competing explanations for the government failure. The most important conclusion of the study is that the poor performance of projects financed by the government in the R\&D-phase is caused by bad financing terms, rather than bad choices of projects. A policy implication is therefore that government institutions should make their financing and loans more marketoriented already in the R\&D-phase.

One objection against the results would be that it is natural that public funded projects have a worse performance than those financed by private investors, since government has to choose among projects that are turned down by private investors. However, recent economic research has shown that this kind of soft government loans are more attractive for inventors and small firms than financing from private venture capitalists and business angels. Thus, it is not likely that government choose among inferior projects, which have been turned down by private investors.

A non-commercialized patent may, of course, also be profitable for the owner, if it serves as a shadow patent - protecting other patents. But this is a strategy mainly used by large firms, which was also indicated by the descriptive statistics in section 3 . Individuals and small firms can simply not afford such a costly strategy.

It would have been preferable to measure the outcome of the patent in money-terms, e.g., in US dollars. However, this is complicated, because most firms have many products in their statement of account, and many individuals do not have any statement of account at all. A suggestion for future research would be to ask the owners to estimate the market value of their patents. These values could then be related to different strategies. 


\section{References}

Amemiya, T., 1981, 'Qualitative Response Models: A Survey', Journal of Economic Literature, Vol. 19, pp. 1483-1536.

Bottazzi, L., M. DaRin and T. Hellmann, 2004, 'The Changing Face of the European Venture Capital Industry: Facts and Analysis', Journal of Private Equity, Vol. 8, n.1.

Braunerhjelm, P., 1999, 'Venture capital, mångfald och tillväxt', Ekonomisk Debatt, Vol. 27, pp. 213-22.

Breschi, S., F. Lissoni and F. Malerba, 2004, 'The Empirical Assessment of Firms' Technological Coherence: Data and Methodology', in The Economics and Management of Technological Diversification, J. Cantwell, A. Gambardella and O. Granstrand (eds.), Routledge, London.

Cutler, R.S., 1984, 'A Study of Patents Resulting from NSF Chemistry Program', World Patenting Information, Vol. 6, pp. 165-69.

Fomby, T.B., R.C. Hill and S.R. Johnson, 1984, Advanced Econometric Methods, SpringerVerlag, New York.

Gompers, P., and Lerner, J., 2001, 'The Venture Capital Revolution', Journal of Economic Perspective, No. 2, pp. 145-168.

Greene, W.H., 1997, Econometric Analysis, $3^{\text {rd }}$ edition, Prentice-Hall, Upper Saddle River, NJ.

Greene, W.H., 2002, Econometric Modeling Guide Vol. 1, Limdep Version 8.0, Econometric Software Inc., Plainview, NY.

Griliches, Z., 1990, 'Patent Statistics as Economic Indicators: A Survey', Journal of Economic Literature, Vol. 28, pp. 1661-1707.

Griliches, Z., B.H. Hall and A. Pakes, 1987, 'The Value of Patents as Indicators of Inventive Activity', In Dasqupta, P. and P. Stoneman (eds), Economic Policy and Technological Performance, Cambridge University Press, Cambridge.

Hall, B.H., 1993, 'The Stock Market Valuation of R\&D Investment During the 1980s', American Economic Review, Vol. 83, pp. 259-64.

Hausmann, J. and D. McFadden, 1984, 'A Specification Test for the Multinomial Logit Model', Econometrica, Vol. 52, pp. 1219-40.

Kaivanto; K. and P. Stoneman, 2006, 'Public Provision of Sales Contingent Claims Backed Finance on SMEs: A Policy Alternative', Research Policy, forthcoming.

Kaplan S. N. and P. Strömberg, 2001, 'Venture Capitals As Principals: Contracting, Screening, and Monitoring', American Economic Review, Vol. 91, pp. 426-30.

Kortum, S. and J. Lerner, 2000, 'Assessing the Contribution of Venture Capital to Innovation', Rand Journal of Economics, Vol. 31, pp. 674-92. 
Maurseth, P.B., 2005, 'Lovely but Dangerous: The Impact of Patent Citations on Patent Renewal', Economics of Innovation and New Technology, Vol. 14, pp. 351-74.

Morgan, R.P., C. Kruytbosch and N. Kannankutty, 2001, 'Patenting and Invention Activity of U.S. Scientists and Engineers in the Academic Sector: Comparisons with Industry', Journal of Technology Transfer, Vol. 26, pp. 173-183.

Pakes, A., 1986, 'Patents as Options: Some Estimates of the Value of Holding European Patent Stocks', Econometrica, Vol. 54, pp. 755-84.

Rossman, J. and B.S. Sanders, 'The Patent Utilization Study', Patent, Trademark and Copyright Journal of Research and Education, Vol. 1, pp. 74-111.

Sanders, B.S., 1962, 'Speedy Entry of Patented Inventions into Commercial Use', Patent, Trademark and Copyright Journal of Research and Education, Vol. 6, pp. 87-116.

Sanders, B.S., 1964, 'Patterns of Commercial Exploitation of Patented Inventions by Large and Small Corporations', Patent, Trademark and Copyright Journal of Research and Education, Vol. 8, pp. 51-92.

Sanders, B.S., J. Rossman and L.J. Harris, 1958, 'The Economic Impact of Patents', Patent, Trademark and Copyright Journal of Research and Education, Vol. 2, pp. 340-62.

Schankerman, M. and A. Pakes, 1986, 'Estimates of the Value of Patent Rights in European Countries During the Post-1950 Period', Economic Journal, Vol. 96, pp. 1052-76.

Schmookler, J., 1966, Invention and Economic Growth, Harvard University Press, Cambridge.

SRI International, 1985, NSF Engineering Program Patent Study, Menlo Park, CA.

Svensson, R., 2002, 'Commercialization of Swedish Patents: A Pilot Study in the Medical and Hygiene Sectors', IUI Working paper No. 583, IUI, Stockholm.

Svensson, R., 2004, 'Commercialization of Patents and External Financing During the R\&DPhase', IUI Working paper No. 624, IUI, Stockholm. 


\section{Appendix: Soft loans provided by Swedish government authorities}

Among the Swedish government institutions, SIC (Foundation Innovation Centre) and NUTEK (Swedish Agency for Economic and Regional Growth) offered loans with soft terms to inventors and high-tech small firms since the beginning of the 1990s until 2005. The loans were given during the R\&D-phase. SIC and NUTEK had a yearly budget of ca. 6-8 MUSD. The loans for individual projects could range from 10,000 to 150,000 USD.

To give soft loans to a firm or an inventor in the R\&D-phase, the government authorities had three selection criteria: 1) the project should have a good chance of success both technically and commercially; 2) the project must be a high-tech project; and 3) the firm should not have more than 100 employees. A difference between the institutions was that SIC-loans were given to a higher degree to inventors and NUTEK-loans to firms.

The government financing could cover up to 50-70\% of the total R\&D-costs depending on which government authority provided the loan. Thus, there was a requirement of co-financing by the borrower or somebody else. However this co-financing was allowed to take the form of unpaid labor incomes. This is a cost which cannot be controlled by the government authority (moral hazard problems). Practically, the government loans could therefore cover more than $80 \%$ of the project's total R\&D-costs.

Three years after the loan was given, the borrower had to submit a report about the status of the project to the government authority. The repayment of the loan was connected to the turnover of the project and repayment possibly started after this report. If the project had failed, the loan was written off with a very high probability. If the project was based on a patent, then a requirement for write-off was that the patent was killed. There were some differences in the loan terms depending on whether the borrower had a firm or not when he or she signed the loan contract.

1) The borrower had already a firm and incomes from other projects. The interest rate was 4 $\%$ above the base rate of The Bank of Sweden. Interest was paid every third month, but not until the final report date ( 3 years after contract). Repayment was $5 \%$ of turnover of the project, or $35 \%$ of royalties in the case of licensing.

2) The borrower had neither a firm nor incomes. The interest rate was $3.75 \%$ above the interest rate of The Bank of Sweden. Interest was paid from the first date and capitalized in the end of each year. Repayment was $7 \%$ of turnover of the project, or $35 \%$ of royalties in the case of licensing. 
Practically, the borrower only needed to repay $50 \%$ of the loan if the borrower had some incomes from the project when the report was submitted. SIC was winded up in 2003 and NUTEK in 2005, but similar loans have been offered by ALMI since 2003. The loan stocks of SIC and NUTEK were overtaken by ALMI. In 2005, ALMI evaluated the repayment of the loans offered by SIC and NUTEK. Only $13 \%$ of the SIC loans and $33 \%$ of the Nutek loans had been repaid. Thus, the default rates of the soft loans were as high as 87 and $67 \%$, respectively.

Also in the Netherlands similar soft loans have been given by TOK (Technisch Ontwikkelingskrediet). TOK had a default rate of $43 \%$ - considerably lower than in the Swedish case. The explanations are that the Dutch loans were also given to medium-sized firms and TOK had harder terms for co-financing and follow-up (Kaivanto and Stoneman, 2006) 
Figure 1. Application year and starting year of commercialization.

Number of patents

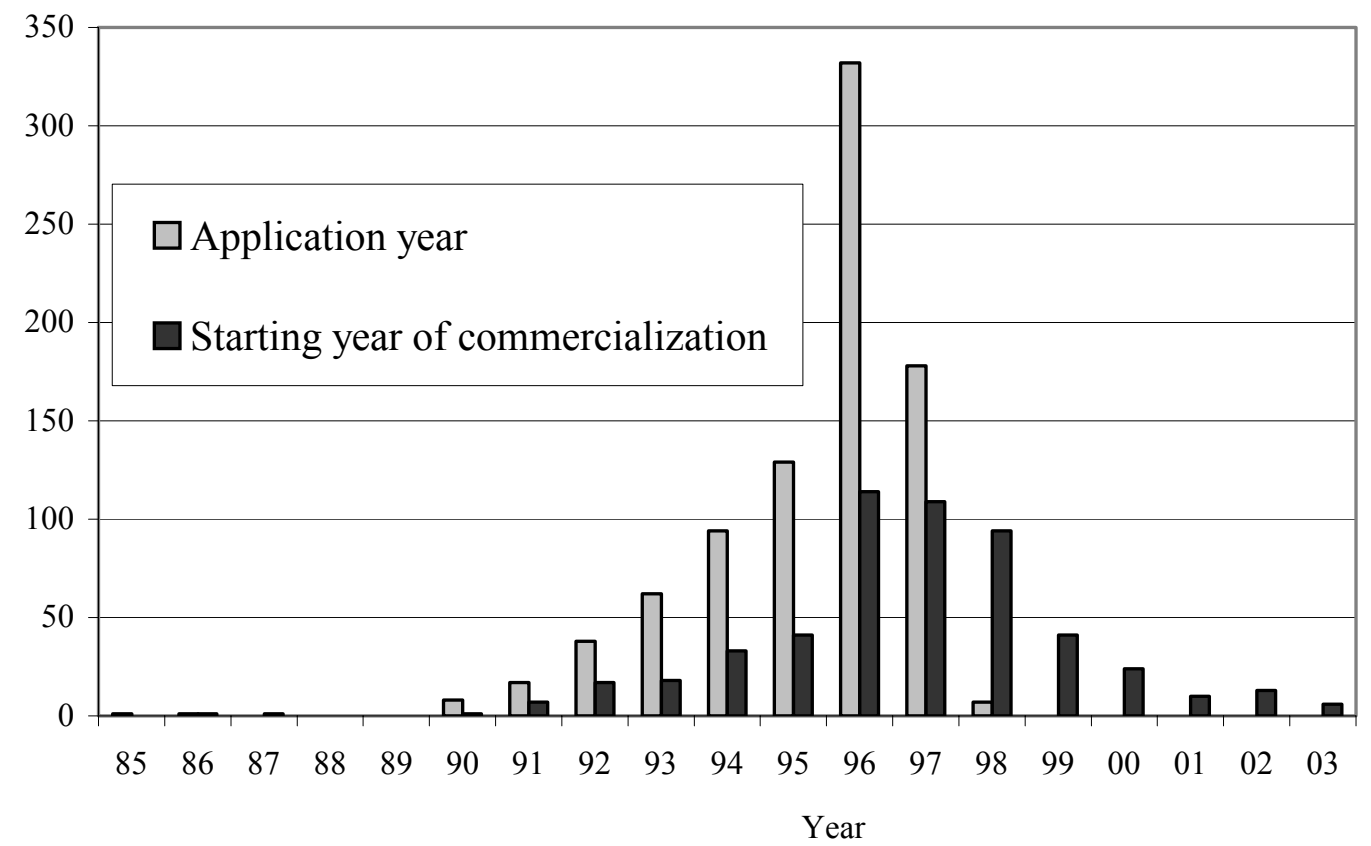


Table 1. Commercialization of patents across firm sizes, number of patents and percent.

\begin{tabular}{lcccc}
\hline & \multicolumn{3}{c}{ Number of patents } & \multirow{2}{*}{$\begin{array}{c}\text { Percent } \\
\text { Kind of firm where the invention was created }\end{array}$} \\
\cline { 2 - 3 } & \multicolumn{2}{c}{ Commercialization } & \multirow{2}{*}{ Total } & Commercialized \\
\cline { 2 - 3 } Medium-sized firms (101-1000 employees) & 77 & 39 & 116 & $66 \%$ \\
Small firms (11-100 employees) & 137 & 64 & 201 & $68 \%$ \\
Close companies (2-10 employees) & 105 & 37 & 142 & $74 \%$ \\
Inventors alone (1-4 inventors) & 211 & 197 & 408 & $52 \%$ \\
\hline Total & $\mathbf{5 3 0}$ & $\mathbf{3 3 7}$ & $\mathbf{8 6 7}$ & $\mathbf{6 1 \%}$ \\
\hline
\end{tabular}

Table 2. Outcome of the commercialization across firm groups, number of patents.

\begin{tabular}{|c|c|c|c|c|c|}
\hline \multirow{2}{*}{$\begin{array}{l}\text { Kind of firm where the invention } \\
\text { was created }\end{array}$} & \multicolumn{4}{|c|}{ Outcome } & \multirow[b]{2}{*}{ Total } \\
\hline & Profit & Break-even & Loss & Uncertain & \\
\hline Medium-sized firms & 53 & 18 & 3 & 3 & 77 \\
\hline Small firms & 95 & 22 & 15 & 5 & 137 \\
\hline Close companies & 48 & 12 & 27 & 18 & 105 \\
\hline Inventors alone & 46 & 43 & 84 & 38 & 211 \\
\hline Total & 242 & 95 & 129 & 64 & 530 \\
\hline
\end{tabular}

Table 3. Commercialization performance across external financing, number of patents.

\begin{tabular}{|c|c|c|c|c|c|}
\hline \multirow{2}{*}{ Commercialization mode } & \multicolumn{4}{|c|}{ Outcome } & \multirow{2}{*}{ Total } \\
\hline & Profit & Break-even & Loss & Uncertain & \\
\hline Private venture capital R\&D-phase & 14 & 2 & 7 & 7 & 30 \\
\hline Government soft loans R\&D-phase & 11 & 9 & 35 & 15 & 70 \\
\hline $\begin{array}{l}\text { Private venture capital } \\
\text { commercialization phase }\end{array}$ & 17 & 5 & 17 & 14 & 53 \\
\hline Government market-oriented loans & 9 & 5 & 19 & 8 & 41 \\
\hline
\end{tabular}
commercialization phase

Note: A specific patent may have more than one source of external financing, both during the R\&D and commercialization phases. 
Table 4. Commercialized patents and patents still alive 2004, number of patents and percent.

\begin{tabular}{lcccc}
\hline \hline \multirow{2}{*}{ Patents still alive 2004 } & \multicolumn{2}{c}{ Commercialized patents latest in 2003 } & $\begin{array}{c}\text { Percent } \\
\text { Commercialized }\end{array}$ \\
\cline { 2 - 4 } & Yes & No & Total & $71 \%$ \\
Yes & 341 & 139 & 480 & $49 \%$ \\
\hline \hline Total & 189 & 198 & 387 & $61 \%$ \\
\hline Percent still alive & 530 & 337 & 867 & \\
\hline
\end{tabular}

Note: Chi-square-value is 44.46 , significant at the 1 percent level for $1 \mathrm{~d} . f$.

Table 5. Outcome of the commercialization across renewed and expired patents, number of patents.

\begin{tabular}{|c|c|c|c|c|c|c|c|c|}
\hline \multirow{3}{*}{\multicolumn{2}{|c|}{ Renewed / expired patents }} & \multicolumn{5}{|c|}{ Commercialized patents } & \multirow{3}{*}{$\begin{array}{l}\text { Not } \\
\text { commer- } \\
\text { cialized }\end{array}$} & \multirow{3}{*}{ Total } \\
\hline & & \multicolumn{4}{|c|}{ Outcome } & \multirow{2}{*}{ Subtotal } & & \\
\hline & & Profit & Break-even & Loss & Uncertain & & & \\
\hline \multirow{4}{*}{$\begin{array}{l}\text { Expired patents, } \\
\text { number of years } \\
\text { after application }\end{array}$} & $1-3$ years & 5 & 5 & 9 & 0 & 19 & 33 & 52 \\
\hline & $4-5$ years & 11 & 7 & 23 & 0 & 41 & 55 & 96 \\
\hline & $6-7$ years & 33 & 17 & 29 & 0 & 79 & 58 & 137 \\
\hline & $>7$ years & 24 & 6 & 20 & 0 & 50 & 52 & 102 \\
\hline \multicolumn{2}{|c|}{ Subtotal of expired patents } & 73 & 35 & 81 & 0 & 189 & 198 & 387 \\
\hline \multicolumn{2}{|c|}{ Patents renewed in 2004} & 169 & 60 & 48 & 64 & 341 & 139 & 480 \\
\hline \multicolumn{2}{|l|}{ Total } & 242 & 95 & 129 & 64 & 530 & 337 & 867 \\
\hline
\end{tabular}


Table 6. Explanatory variables and hypotheses.

\begin{tabular}{|c|c|c|c|c|}
\hline \multirow{2}{*}{$\begin{array}{l}\text { Variable } \\
\text { denotation }\end{array}$} & \multirow[b]{2}{*}{ Variable description } & \multirow{2}{*}{$\frac{\text { Hypotheses }}{\text { PROFIT }}$} & \multicolumn{2}{|c|}{ Statistics $(n=466)$} \\
\hline & & & Mean & Std dev. \\
\hline GOVRD & Dummy which equals 1 if part of R\&D financed by government, and 0 otherwise & - & 0.118 & 0.323 \\
\hline PRIVRD & Dummy which equals 1 if part of R\&D financed by private venture capital, and 0 otherwise & ? & 0.049 & 0.217 \\
\hline OTHRD & $\begin{array}{l}\text { Dummy which equals } 1 \text { if part of R\&D financed by universities / research foundations, and } 0 \\
\text { otherwise }\end{array}$ & $?$ & 0.026 & 0.159 \\
\hline GOVCOM & Dummy which equals 1 if part of commercialization financed by government, and 0 otherwise & $?$ & 0.071 & 0.257 \\
\hline PRIVCOM & $\begin{array}{l}\text { Dummy which equals } 1 \text { if part of commercialization financed by private venture capital, and } 0 \\
\text { otherwise }\end{array}$ & $?$ & 0.084 & 0.277 \\
\hline FIRM1 & Dummy which equals 1 for medium-sized firms (101-1000 employees), and 0 otherwise & + & 0.159 & 0.366 \\
\hline FIRM2 & Dummy which equals 1 for small firms (11-100 employees), and 0 otherwise & + & 0.283 & 0.451 \\
\hline FIRM3 & Dummy which equals 1 for close companies (2-10 employees), and 0 otherwise & + & 0.187 & 0.390 \\
\hline SELL & Dummy which equals 1 if the owners sold the patent, and 0 otherwise & $?$ & 0.043 & 0.203 \\
\hline LICENSE & Dummy which equals 1 if the owners licensed the patent, and 0 otherwise & $?$ & 0.090 & 0.287 \\
\hline NEW & Dummy which equals 1 if the owners started a new firm, and 0 otherwise & - & 0.105 & 0.307 \\
\hline COMYEAR & Starting year of the commercialization & $?$ & 1997 & 2.24 \\
\hline WAITYEAR & Number of years between patent application and start of commercialization & $?$ & 1.33 & 1.64 \\
\hline ACTIVE & Dummy which equals 1 if the inventors are active during the commercialization, and 0 otherwise & + & 0.862 & 0.345 \\
\hline REPLACE & Dummy which equals 1 if the product replaced a previous product for the owners & + & 0.082 & 0.274 \\
\hline MOREPAT & Dummy which equals 1 if the owners have more substituting patents, and 0 otherwise & + & 0.453 & 0.498 \\
\hline PARTSYSTEM & Dummy which equals 1 if the product is a part of a larger system, and 0 otherwise & $?$ & 0.159 & 0.366 \\
\hline INVNMBR & Number of inventors & $?$ & 1.30 & 0.614 \\
\hline KOMPL & Dummy which equals 1 if complementing patents are need to create a product, and 0 otherwise & $?$ & 0.279 & 0.449 \\
\hline$S X$ & Share of inventors, who are females & $?$ & 0.021 & 0.132 \\
\hline ETH & Share of inventors with an ethnical background other than Western European or North-American & ? & 0.023 & 0.147 \\
\hline
\end{tabular}

Note: The signs "+", "- " and "?" indicate a positive, a negative and an unsettled expected influence on the profit level. 
Table 7. Empirical estimations of the ordered probit model.

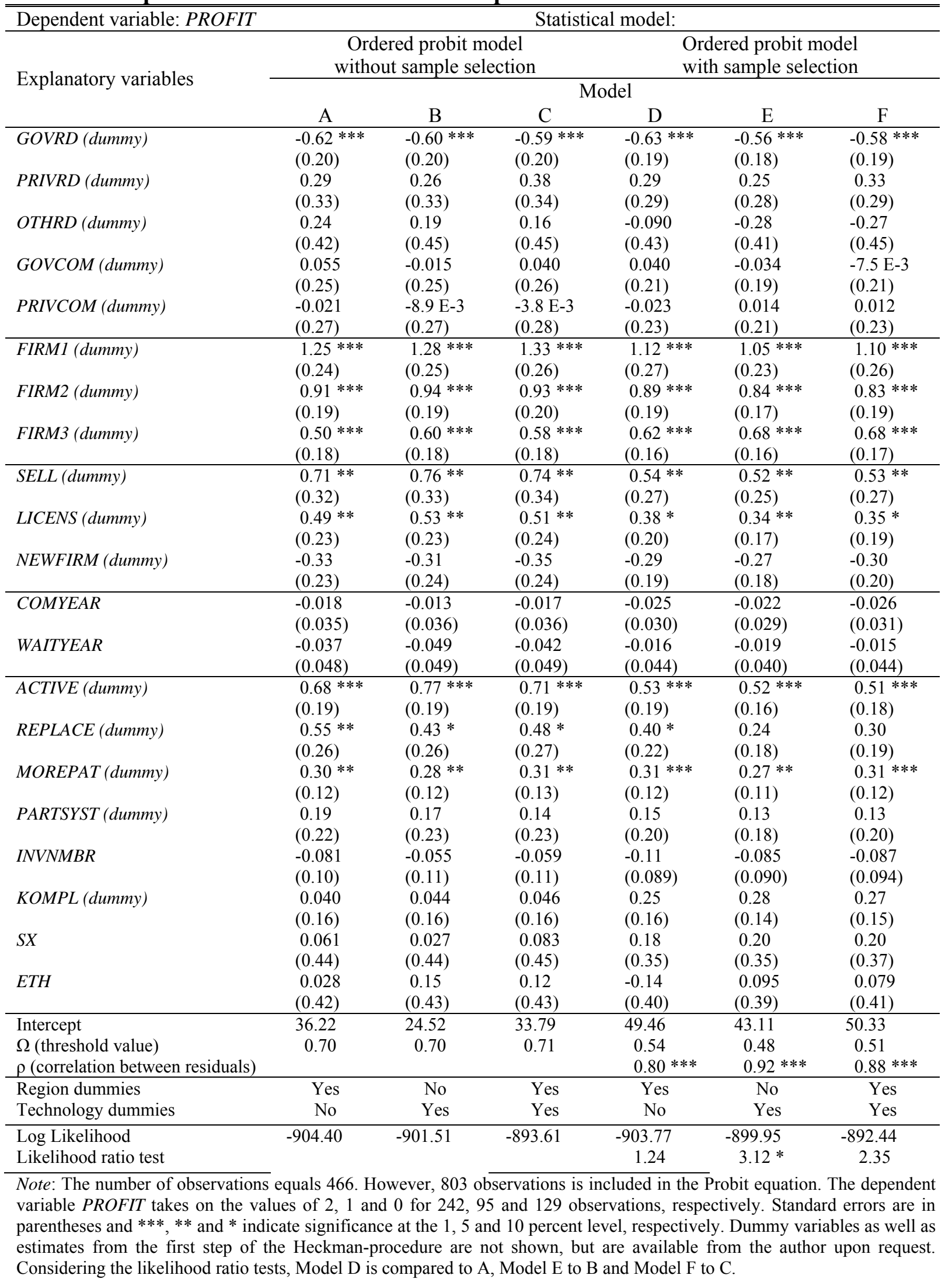


Table 8. Separate effects of government financing for individuals and firms.

\begin{tabular}{|c|c|c|c|c|c|c|c|}
\hline \multicolumn{3}{|c|}{ Dependent variable: $P R O F I T$} & \multicolumn{4}{|c|}{ Statistical model: Ordered probit model } & \multirow[b]{3}{*}{$\mathrm{F}$} \\
\hline \multirow{2}{*}{\multicolumn{2}{|c|}{ Explanatory variables }} & \multicolumn{5}{|c|}{ Model } & \\
\hline & & A & B & C & D & $\mathrm{E}$ & \\
\hline \multirow{3}{*}{ GOVRD } & Individuals & $\begin{array}{l}-0.46 * * \\
(0.22)\end{array}$ & $\begin{array}{l}-0.47 * * \\
(0.22)\end{array}$ & $\begin{array}{l}-0.45 * * \\
(0.23)\end{array}$ & $\begin{array}{l}-0.51 * * \\
(0.23)\end{array}$ & $\begin{array}{l}-0.47 * * \\
(0.19)\end{array}$ & $\begin{array}{l}-0.48 * * \\
(0.21)\end{array}$ \\
\hline & Firms & $\begin{array}{l}-1.10 * * * \\
(0.39)\end{array}$ & $\begin{array}{l}-1.02 * * \\
(0.40)\end{array}$ & $\begin{array}{l}-1.03 * * \\
(0.41)\end{array}$ & $\begin{array}{l}-1.01 * * * \\
(0.33)\end{array}$ & $\begin{array}{l}-0.86 * * * \\
(0.32)\end{array}$ & $\begin{array}{l}-0.91 * * \\
(0.34)\end{array}$ \\
\hline & Difference & $\begin{array}{c}0.64 \\
(0.44)\end{array}$ & $\begin{array}{c}0.56 \\
(0.45)\end{array}$ & $\begin{array}{c}0.58 \\
(0.46)\end{array}$ & $\begin{array}{c}0.50 \\
(0.36)\end{array}$ & $\begin{array}{c}0.39 \\
(0.34)\end{array}$ & $\begin{array}{c}0.44 \\
(0.36)\end{array}$ \\
\hline
\end{tabular}

Table 9. Marginal effects of explanatory variables. Ordered probit, Models $\mathbf{C}$ and F.

\begin{tabular}{|c|c|c|c|c|c|c|}
\hline \multirow{3}{*}{ Dummy variables } & \multicolumn{6}{|c|}{ Marginal effect on probabilities when dummy variables increase from 0 to 1.} \\
\hline & \multicolumn{3}{|c|}{ Model C } & \multicolumn{3}{|c|}{ Model F } \\
\hline & $P(0)$ & $P(1)$ & $P(2)$ & $P(0)$ & $P(1)$ & $P(2)$ \\
\hline GOVRD & 0.20 & 0.03 & -0.23 & 0.22 & -0.04 & -0.18 \\
\hline Individuals & 0.15 & 0.03 & -0.18 & 0.19 & -0.04 & -0.15 \\
\hline Firms & 0.37 & 0.00 & -0.37 & 0.33 & -0.08 & -0.25 \\
\hline FIRM1 & $-0,26$ & -0.18 & 0.44 & -0.39 & -0.03 & 0.42 \\
\hline FIRM2 & -0.23 & -0.11 & 0.34 & -0.32 & 0.01 & 0.31 \\
\hline FIRM3 & -0.15 & -0.07 & 0.22 & -0.26 & 0.00 & 0.26 \\
\hline SELL & -0.16 & -0.11 & 0.27 & -0.20 & -0.00 & 0.20 \\
\hline LICENSE & -0.12 & -0.07 & 0.19 & -0.14 & 0.01 & 0.13 \\
\hline$N E W$ & 0.12 & 0.02 & -0.14 & 0.12 & -0.02 & -0.10 \\
\hline ACTIVE & -0.25 & $\begin{array}{l}-0.02 \\
\end{array}$ & 0.27 & -0.20 & 0.04 & 0.16 \\
\hline REPLACE & -0.12 & -0.06 & 0.19 & -0.12 & 0.01 & 0.11 \\
\hline MOREPAT & -0.09 & -0.03 & 0.12 & -0.12 & 0.01 & 0.11 \\
\hline
\end{tabular}

Note: All marginal effects are calculated around the means of the $\mathbf{x}$ :s. Similar marginal effects were obtained for Models A, B, D and E, which are available from the author on request. 